\title{
DESIGN OF 6-BIT FLASH ANALOG TO DIGITAL CONVERTER USING VARIABLE SWITCHING VOLTAGE CMOS COMPARATOR
}

\author{
Gulrej Ahmed ${ }^{1}$ and Rajendra Kumar Baghel ${ }^{2}$ \\ Department of Electronics and Communication Engineering, \\ Maulana Azad National Institute of Technology (MANIT), Bhopal, India
}

\begin{abstract}
This paper presents the design of 6-bit flash analog to digital Converter (ADC) using the new variable switching voltage (VSV) comparator. In general, Flash ADCs attain the highest conversion speed at the cost of high power consumption. By using the new VSV comparator, the designed 6-bit Flash ADC exhibits significant improvement in terms of power and speed of previously reported Flash ADCs. The simulation result shows that the converter consumes peak power $2.1 \mathrm{~mW}$ from a $1.2 \mathrm{~V}$ supply and achieves the speed of $1 \mathrm{GHz}$ in a $65 \mathrm{~nm}$ standard CMOS process. The measurement of maximum differential and integral nonlinearities (DNL and INL) of the Flash ADC are 0.3 LSB and 0.6 LSB respectively.
\end{abstract}

\section{KEYWORDS}

Variable switching voltage, threshold inverter quantization, comparator, Flash ADC.

\section{INTRODUCTION}

Analog-to-digital converter (ADC) has become essential structure for most of the electronics and communication systems. Comparator constitutes the main component in analog to digital conversion $(\mathrm{ADC})$. It is basically the first stage in $\mathrm{ADC}$, which converts the signal from analog to digital domain. The Flash ADC is the fastest ADC among all types of available ADC architectures. An N-Bit Flash ADC employs the $2^{\mathrm{N}}-1$ comparators for data conversion. However, these comparators consume large power as they work simultaneously in parallel fashion. The Flash ADC also requires resistor ladder circuit or capacitor array circuit for reference voltage generation [2], which again makes the converter more power hungry \& therefore Flash ADC consumes highest power among all types of ADCs. For low power data conversion circuits, the power dissipation has become one of the most important limitations. In reality, power efficiency has been considered as an essential design criterion in many battery employed applications such as wireless sensor node, pacemakers and other implanted RFID chips as biomedical imaging devices in the human body [4]. The objective in such cases is minimum power consumption for maximum battery life time. The designed 6-Bit Flash ADC in this paper meets the requirement for such low power applications.

\section{RELATED RESEARCH WORK}

In order to minimize the power consumption and improve the performance matrices of ADC, the researches basically focus on the optimization of the comparator circuit. In this section, the 
International Journal of VLSI design \& Communication Systems (VLSICS) Vol.5, No.3, June 2014

research work under discussion contains only Flash ADC design using threshold voltage scaling of the comparator. In [5], a static inverter circuit has been explored as programmable logical buffer circuit and it has been suggested that the logic threshold voltage of CMOS inverter can be programmed to different specific logical voltages. These variable logical voltages can be evaluated mathematically. In [7], the thorough theoretical background of static CMOS inverter is elaborated. Using the aforementioned concept, a CMOS inverter has been realized as a threshold inverter quantization (TIQ) comparator [6]. The design of proposed TIQ comparator is a simpler as compared to traditional analog differential comparator. The basic thought is to simply apply the digital inverter as an analog voltage comparator. This also eliminates the resistive reference voltage circuit in Flash ADC. Thereby, static power consumption by resistive ladder circuit is removed. Inspired by the threshold voltage scaling, a reduced kickback comparator has been reported in literature [9]. Basically, it is a differential type of comparator, which can be designed with inbuilt threshold voltages. The design presented in [10] explored the TIQ comparator for 6bit Flash ADC. It was basically implemented for system on chip (SOC) applications. The designed ADC was simpler and faster than other Flash ADCs. In this paper, the same research has been extended with the modified version of the comparator. The simulation results are better than the earlier reported works and the design 6-bit Flash ADC excels in terms of speed and power consumption.

\section{COMPARATOR}

The function of a comparator is to generate an output voltage, which is high or low depending on whether the amplitude of the input is greater or lesser than a reference signal. It produces a binary output whose value is based on a comparison of two analog inputs. Typical comparators have differential type of architecture, and they can be further divided into open-loop and dynamic comparators. The open-loop comparators are fundamentally operational amplifier [4]. Dynamic comparators use positive feedback similar to flip-flops to accomplish the comparison of the magnitude between input and the external reference signal. However these differential types of comparator are intrinsically complex in design and consume high amount of power. On the other hand, single ended comparator architecture may be deployed as an analog comparator instead of using a whole analog block of comparator. The threshold inverter quantization (TIQ) comparators have been used to design the Flash ADC. The TIQ inverter based comparator consists of two cascaded inverters as shown in figure 1.

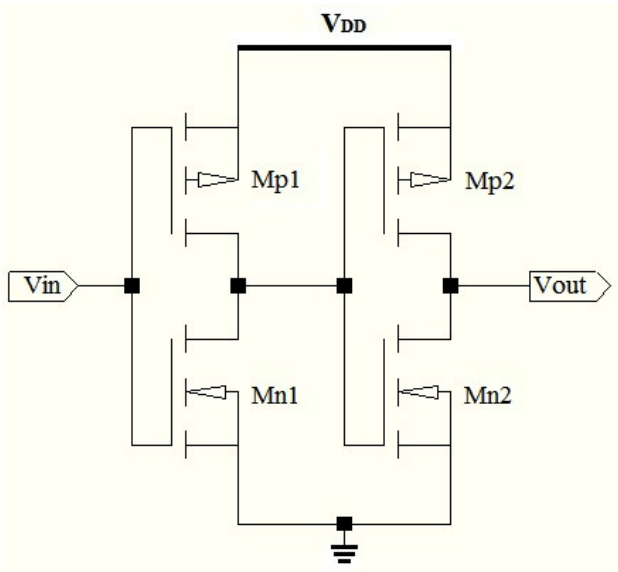

Figure 1. TIQ Comparator [6] 
International Journal of VLSI design \& Communication Systems (VLSICS) Vol.5, No.3, June 2014

The inverter requires lesser number of transistors as compared to traditional comparator. In fact, a traditional comparator requires two input signal, while inverter based comparator requires only one input signal. The logic reference or switching voltage is generated by the inverter itself [5]. Graphically, the switching voltage can be identified at the intersection of the input voltage (Vin) and the output voltage (Vout) signal. At this point, both the transistor PMOS and NMOS are in the saturation region. By equating the drain current of devices, the switching threshold voltage can be determined. The mathematical formula for these switching voltages is given by the following equation [7].

$$
V_{s v}=\frac{\left(\mathrm{V}_{\mathrm{DD}}-\left\lfloor\mathrm{V}_{\mathrm{tp} 1}\right\rfloor\right) \sqrt{\mathrm{k} \frac{\mathrm{w}_{\mathrm{p}}}{\mathrm{w}_{\mathrm{n}}}}+\mathrm{V}_{\mathrm{tn} 1}}{\sqrt{\mathrm{k} \frac{\mathrm{w}_{\mathrm{p}}}{\mathrm{w}_{\mathrm{n}}}}+1}
$$

Wherein, $\mathrm{k}$ denotes the mobility ratio of hole and electron, $\mathrm{w}_{\mathrm{p}} \& \mathrm{w}_{\mathrm{n}}$ are the channel width of PMOS (Mp1) \& NMOS (Mn1) respectively, $V_{t n 1} \& V_{t p 1}$ are the threshold voltages of the devices $\mathrm{Mn} 1$ and $\mathrm{Mp} 1$ respectively. Further the equation can be simplified in terms of the channel width ratio of Mp1 and Mn1.

$$
V_{s v}=\frac{\left(\mathrm{V}_{\mathrm{DD}}-\left\lfloor\mathrm{V}_{\mathrm{tp} 1}\right\rfloor\right) \sqrt{\mathrm{k} \mathrm{W}_{\mathrm{r}}}+\mathrm{V}_{\mathrm{tn} 1}}{\sqrt{\mathrm{kw}_{\mathrm{r}}}+1}
$$

Where, $\mathrm{w}_{\mathrm{r}}$ is the ratio of channel width of devices Mp1 and Mn1. While driving the equation of switching voltage, it has been assumed that both transistors PMOS \& NMOS have the same channel length. The logic threshold voltage of a CMOS inverter is determined by the channel width ratio $\mathrm{W}_{\mathrm{r}}$ of the PMOS and NMOS transistors. However at $65 \mathrm{~nm}$ standard CMOS process, the switching voltage is not governed by the equation (2), it is due to the fact that short channel devices do not follow the square law relation and in such case, the switching voltage is controlled by effective resistance of the devices [8], it is therefore given by following equation.

$$
V_{s v}=V_{D D} \frac{\mathrm{r}_{\mathrm{mn} 1}}{\mathrm{r}_{\mathrm{mn} 1}+\mathrm{r}_{\mathrm{mp} 1}}
$$

Where $r_{m n 1}$ and $r_{m p 1}$ are the effective switching resistances of NMOS (Mn1) and PMOS (Mp1) transistors of the first stage inverter at channel length $(\mathrm{L})=65 \mathrm{~nm}$, respectively. The resistance $r_{m n 1}$ and $r_{m p 1}$ are the function aspect ratio (W/L) of the devices, thus the switching voltages can be programmed to specific values by varying the aspect ratio.

\subsection{VARIABLE SWITCHING VOLTAGE COMPARATOR}

The proposed variable switching voltage (VSV) comparator is shown in figure 2. The proposed comparator comprises eight numbers of transistors. However the number of transistor has been doubled as compared to traditional TIQ comparator. In spite of this, the proposed comparator consumes lesser power than the TIQ comparator. It is due to the fact that, the addition of M1 and M2 provides negative feedback in the comparator. 


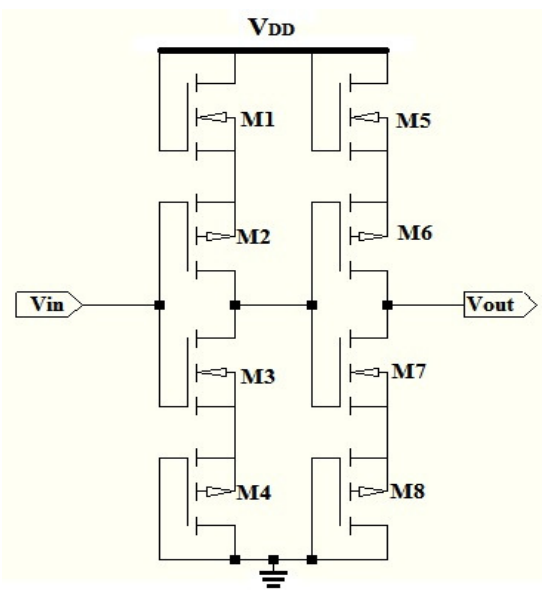

Figure 2. Proposed VSV Comparator

This causes reduction in the drain current of Mn1 and Mp1 of the first stage. This in turn decreases the power consumption of the first stage. The same remark is applied to the second stage of the comparator. In fact, the second stage provides sharper switching of the logical voltages and it is used to invert the output of the first stage. Note that the devices M1, M4, M5 and M8 are always in saturation because drain and gate terminals are at the same potential i.e. $\mathrm{V}_{\mathrm{G}}=\mathrm{V}_{\mathrm{D}}$. The saturated device offers an active resistance, which can be determined by its transconductance $\left(g_{m}\right)$. For the NMOS device, it is given by the following equation.

$$
g_{m}=\frac{\partial I_{D}}{\partial V_{g s}}=\sqrt{2\left(\frac{w}{L}\right)_{n} \mu_{n} C_{\mathrm{oX}} \mathrm{I}_{\mathrm{D}}}
$$

This can be further simplified in terms of the aspect ratio $\left(A_{r n}\right)$ and process transconductance $\left(k_{n}^{\prime}\right)$ of NMOS device.

$$
g_{m}=\sqrt{2 A_{r n} k_{n}^{\prime} \mathrm{I}_{\mathrm{D}}}
$$

Similarly for the PMOS device, the transconductance $\left(g_{m}\right)$ may be given as.

$$
g_{m}=\sqrt{2 A_{r p} k_{p}^{\prime} I_{D}}
$$

The switching voltage of first stage of the proposed comparator can be evaluated in the same manner as in equation 3 .

$$
V_{s v}=V_{D D} \frac{\mathrm{r}_{\mathrm{m} 3}+\frac{1}{\mathrm{~g}_{\mathrm{m} 4}}}{\frac{1}{\mathrm{~g}_{\mathrm{m} 1}}+\mathrm{r}_{\mathrm{m} 2}+\mathrm{r}_{\mathrm{m} 3}+\frac{1}{\mathrm{~g}_{\mathrm{m} 4}}}
$$


International Journal of VLSI design \& Communication Systems (VLSICS) Vol.5, No.3, June 2014

Where $1 / g_{\mathrm{m} 1} \& 1 / g_{\mathrm{m} 4}$ are the active resistance of M1 and M4 respectively, while $r_{\mathrm{m} 2} \& r_{\mathrm{m} 3}$ are the effective switching resistances of M2 and M3 transistors. Since the switching resistance of a transistor depends on its channel width, therefore the width of the devices M1, M2 and M3, M4 is varied to obtain the 63 different switching voltages as shown in figure 3.

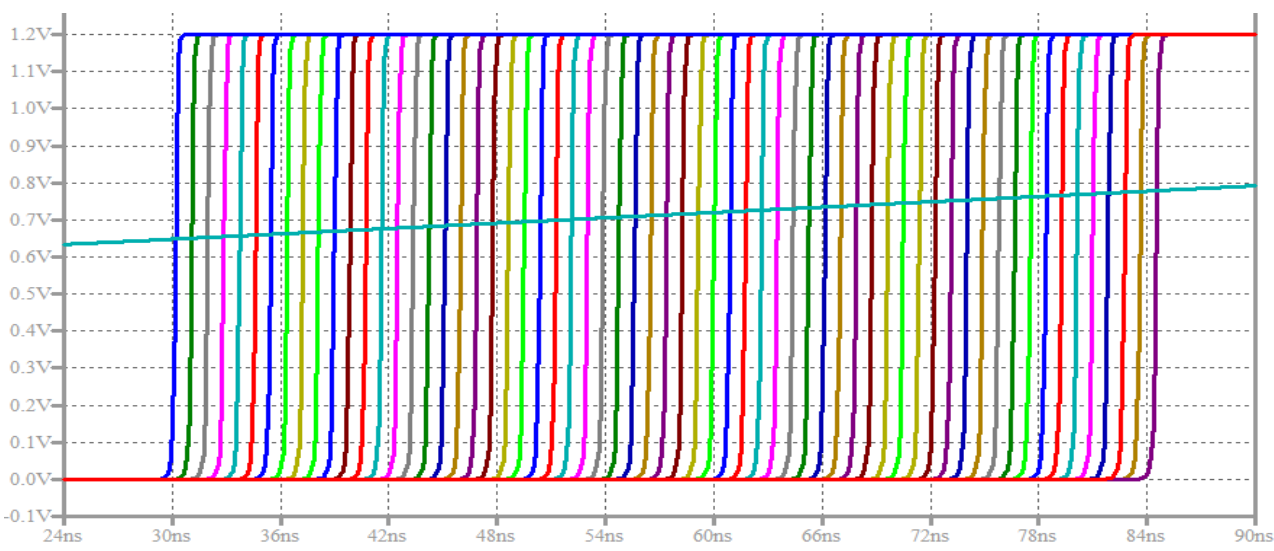

Figure 3. Switching voltages of 6-bit Flash ADC

Using the proposed comparator, a low-power 6-bit Flash ADC is designed and simulated. A comparative analysis is also presented to justify the power reduction in the proposed comparator.

\subsection{Flash ADC}

The generalized block diagram of N-bit Flash ADC is shown in the figure 4. A 6-bit Flash ADC requires 63 numbers of comparator at the input side of the block diagram. An analog input voltage (Vin) goes through each comparator, the comparators compare the input voltage with internal reference voltages, which are determined by the aspect ratio of CMOS transistors of VSV Comparator. These comparators work simultaneously. The comparator's output will be either ' 1 ' or ' 0 ' depending on internal reference voltage of the comparator.

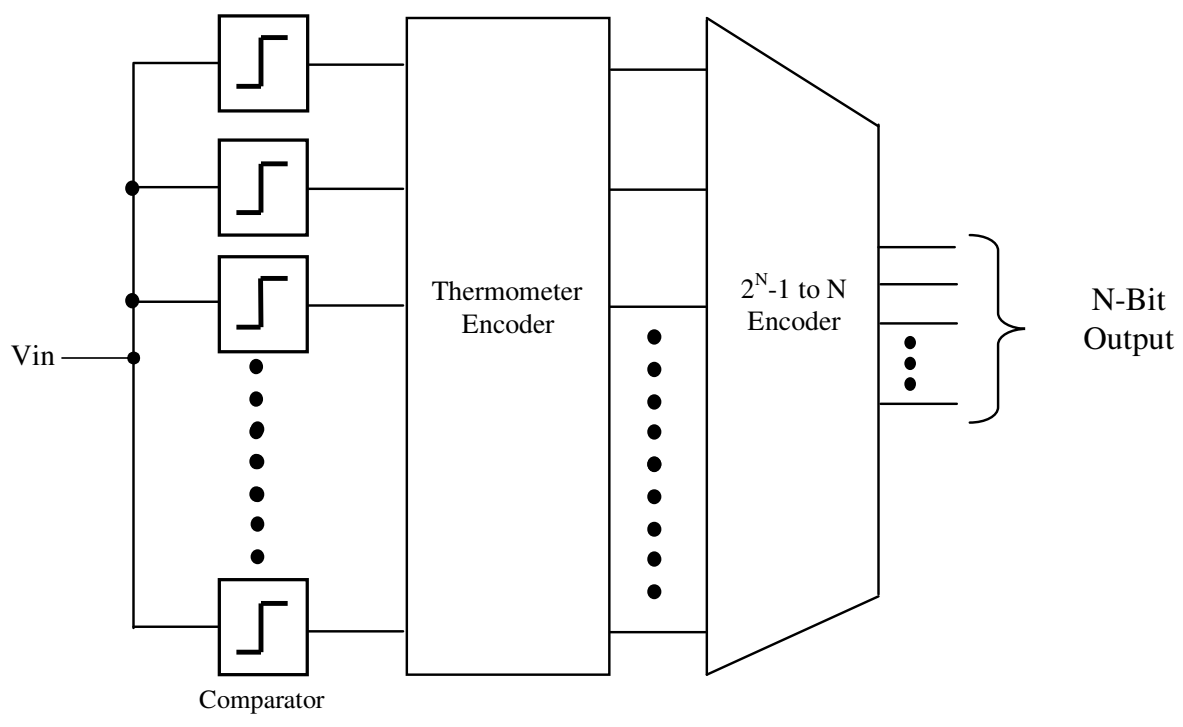

Figure 4. VSV comparator based Flash ADC Architecture 
International Journal of VLSI design \& Communication Systems (VLSICS) Vol.5, No.3, June 2014

For 6-bit Flash ADC, the digital switching signals (thermometer codes) are produced by the array of 63 comparators. The thermometer codes are converted into intermediate codes to minimize the bubble error in the code. The output of the thermometer encoder is shown in figure 6.

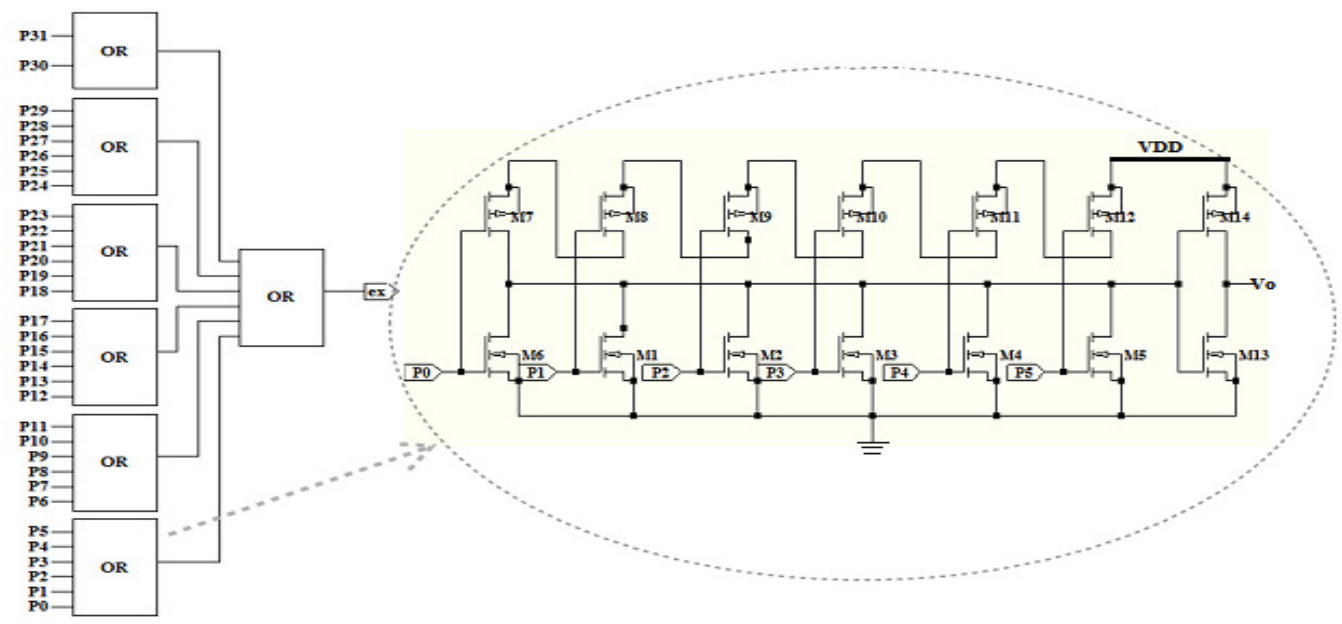

Figure 5. Second Stage Encoder

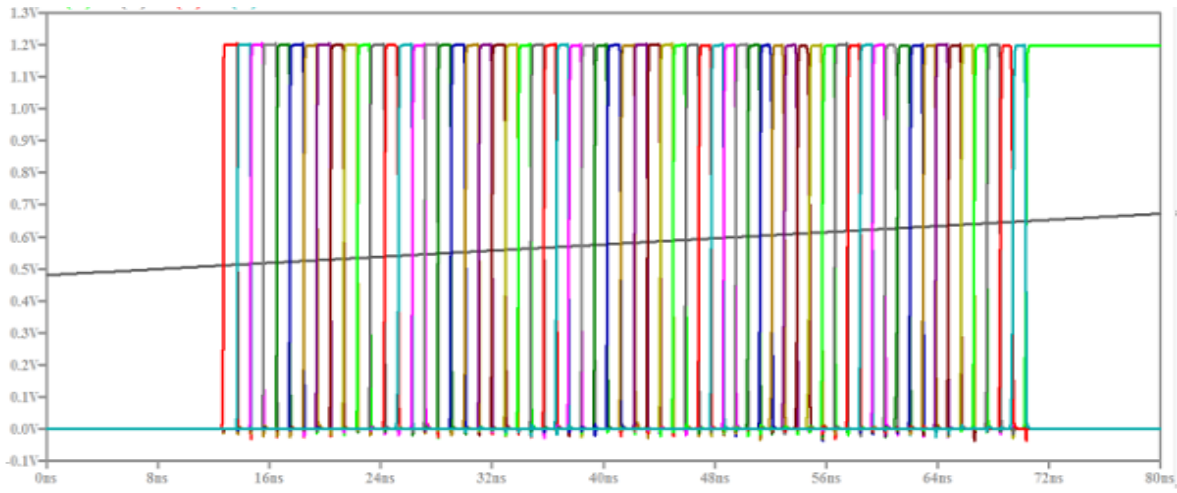

Figure 6. Waveform of 63 Intermediate codes

The intermediate codes are fed to $2^{\mathrm{N}}-1$ to $\mathrm{N}$ encoder block. The encoder performs second step of encoding as shown in figure 5. Basically, it encodes the single bit. There are as such 6 encoder blocks associated with each bit for performing the encoding process. Table 1 summarizes this final encoding process for all 6-bits.

Table 1. Encoder Input Combinations

\begin{tabular}{|c|c|c|c|c|c|c|}
\hline \multirow{2}{*}{ Encoder Input } & \multicolumn{7}{|c|}{ Encoder Output } \\
\cline { 2 - 7 } & $\mathbf{E}_{\mathbf{5}}$ & $\mathbf{E}_{\mathbf{4}}$ & $\mathbf{E}_{\mathbf{3}}$ & $\mathbf{E}_{\mathbf{2}}$ & $\mathbf{E}_{\mathbf{1}}$ & $\mathbf{E}_{\mathbf{0}}$ \\
\hline $\mathrm{P}_{0}$ & $\mathrm{I}_{32}$ & $\mathrm{I}_{16}$ & $\mathrm{I}_{8}$ & $\mathrm{I}_{4}$ & $\mathrm{I}_{2}$ & $\mathrm{I}_{1}$ \\
\hline $\mathrm{P}_{1}$ & $\mathrm{I}_{33}$ & $\mathrm{I}_{17}$ & $\mathrm{I}_{9}$ & $\mathrm{I}_{5}$ & $\mathrm{I}_{3}$ & $\mathrm{I}_{3}$ \\
\hline $\mathrm{P}_{2}$ & $\mathrm{I}_{34}$ & $\mathrm{I}_{18}$ & $\mathrm{I}_{10}$ & $\mathrm{I}_{6}$ & $\mathrm{I}_{6}$ & $\mathrm{I}_{5}$ \\
\hline $\mathrm{P}_{3}$ & $\mathrm{I}_{35}$ & $\mathrm{I}_{19}$ & $\mathrm{I}_{11}$ & $\mathrm{I}_{7}$ & $\mathrm{I}_{7}$ & $\mathrm{I}_{7}$ \\
\hline $\mathrm{P}_{4}$ & $\mathrm{I}_{36}$ & $\mathrm{I}_{20}$ & $\mathrm{I}_{12}$ & $\mathrm{I}_{12}$ & $\mathrm{I}_{10}$ & $\mathrm{I}_{9}$ \\
\hline
\end{tabular}


International Journal of VLSI design \& Communication Systems (VLSICS) Vol.5, No.3, June 2014

\begin{tabular}{|c|c|c|c|c|c|c|}
\hline $\mathrm{P}_{5}$ & $\mathrm{I}_{37}$ & $\mathrm{I}_{21}$ & $\mathrm{I}_{13}$ & $\mathrm{I}_{13}$ & $\mathrm{I}_{11}$ & $\mathrm{I}_{11}$ \\
\hline $\mathrm{P}_{6}$ & $\mathrm{I}_{38}$ & $\mathrm{I}_{22}$ & $\mathrm{I}_{14}$ & $\mathrm{I}_{14}$ & $\mathrm{I}_{14}$ & $\mathrm{I}_{13}$ \\
\hline $\mathrm{P}_{7}$ & $\mathrm{I}_{39}$ & $\mathrm{I}_{23}$ & $\mathrm{I}_{15}$ & $\mathrm{I}_{15}$ & $\mathrm{I}_{15}$ & $\mathrm{I}_{15}$ \\
\hline $\mathrm{P}_{8}$ & $\mathrm{I}_{40}$ & $\mathrm{I}_{24}$ & $\mathrm{I}_{24}$ & $\mathrm{I}_{20}$ & $\mathrm{I}_{18}$ & $\mathrm{I}_{17}$ \\
\hline $\mathrm{P}_{9}$ & $\mathrm{I}_{41}$ & $\mathrm{I}_{25}$ & $\mathrm{I}_{25}$ & $\mathrm{I}_{21}$ & $\mathrm{I}_{19}$ & $\mathrm{I}_{19}$ \\
\hline $\mathrm{P}_{10}$ & $\mathrm{I}_{42}$ & $\mathrm{I}_{26}$ & $\mathrm{I}_{26}$ & $\mathrm{I}_{22}$ & $\mathrm{I}_{22}$ & $\mathrm{I}_{21}$ \\
\hline $\mathrm{P}_{11}$ & $\mathrm{I}_{43}$ & $\mathrm{I}_{27}$ & $\mathrm{I}_{27}$ & $\mathrm{I}_{23}$ & $\mathrm{I}_{23}$ & $\mathrm{I}_{23}$ \\
\hline $\mathrm{P}_{12}$ & $\mathrm{I}_{44}$ & $\mathrm{I}_{28}$ & $\mathrm{I}_{28}$ & $\mathrm{I}_{28}$ & $\mathrm{I}_{26}$ & $\mathrm{I}_{25}$ \\
\hline $\mathrm{P}_{13}$ & $\mathrm{I}_{45}$ & $\mathrm{I}_{29}$ & $\mathrm{I}_{29}$ & $\mathrm{I}_{29}$ & $\mathrm{I}_{27}$ & $\mathrm{I}_{27}$ \\
\hline $\mathrm{P}_{14}$ & $\mathrm{I}_{46}$ & $\mathrm{I}_{30}$ & $\mathrm{I}_{30}$ & $\mathrm{I}_{30}$ & $\mathrm{I}_{30}$ & $\mathrm{I}_{29}$ \\
\hline$P_{15}$ & $\mathrm{I}_{47}$ & $\mathrm{I}_{31}$ & $\mathrm{I}_{31}$ & $\mathrm{I}_{31}$ & $\mathrm{I}_{31}$ & $\mathrm{I}_{31}$ \\
\hline $\mathrm{P}_{16}$ & $\mathrm{I}_{48}$ & $\mathrm{I}_{48}$ & $\mathrm{I}_{40}$ & $\mathrm{I}_{36}$ & $\mathrm{I}_{34}$ & $\mathrm{I}_{33}$ \\
\hline $\mathrm{P}_{17}$ & $\mathrm{I}_{49}$ & $\mathrm{I}_{49}$ & $\mathrm{I}_{41}$ & $\mathrm{I}_{37}$ & $\mathrm{I}_{35}$ & $\mathrm{I}_{35}$ \\
\hline $\mathrm{P}_{18}$ & $\mathrm{I}_{50}$ & $\mathrm{I}_{50}$ & $\mathrm{I}_{42}$ & $\mathrm{I}_{38}$ & $\mathrm{I}_{38}$ & $\mathrm{I}_{37}$ \\
\hline $\mathrm{P}_{19}$ & $\mathrm{I}_{51}$ & $\mathrm{I}_{51}$ & $\mathrm{I}_{43}$ & $\mathrm{I}_{39}$ & $\mathrm{I}_{39}$ & $\mathrm{I}_{39}$ \\
\hline $\mathrm{P}_{20}$ & $\mathrm{I}_{52}$ & $\mathrm{I}_{52}$ & $\mathrm{I}_{44}$ & $\mathrm{I}_{44}$ & $\mathrm{I}_{42}$ & $\mathrm{I}_{41}$ \\
\hline $\mathrm{P}_{21}$ & $\mathrm{I}_{53}$ & $\mathrm{I}_{53}$ & $\mathrm{I}_{45}$ & $\mathrm{I}_{45}$ & $\mathrm{I}_{43}$ & $\mathrm{I}_{43}$ \\
\hline $\mathrm{P}_{22}$ & $\mathrm{I}_{54}$ & $\mathrm{I}_{54}$ & $\mathrm{I}_{46}$ & $\mathrm{I}_{46}$ & $\mathrm{I}_{46}$ & $\mathrm{I}_{45}$ \\
\hline $\mathrm{P}_{23}$ & $\mathrm{I}_{55}$ & $\mathrm{I}_{55}$ & $\mathrm{I}_{47}$ & $\mathrm{I}_{47}$ & $\mathrm{I}_{47}$ & $\mathrm{I}_{47}$ \\
\hline $\mathrm{P}_{24}$ & $\mathrm{I}_{56}$ & $\mathrm{I}_{56}$ & $\mathrm{I}_{56}$ & $\mathrm{I}_{52}$ & $\mathrm{I}_{50}$ & $\mathrm{I}_{49}$ \\
\hline $\mathrm{P}_{25}$ & $\mathrm{I}_{57}$ & $\mathrm{I}_{57}$ & $\mathrm{I}_{57}$ & $\mathrm{I}_{53}$ & $\mathrm{I}_{51}$ & $\mathrm{I}_{51}$ \\
\hline $\mathrm{P}_{26}$ & $\mathrm{I}_{58}$ & $\mathrm{I}_{58}$ & $\mathrm{I}_{58}$ & $\mathrm{I}_{54}$ & $\mathrm{I}_{54}$ & $\mathrm{I}_{53}$ \\
\hline $\mathrm{P}_{27}$ & $\mathrm{I}_{59}$ & $\mathrm{I}_{59}$ & $\mathrm{I}_{59}$ & $\mathrm{I}_{55}$ & $\mathrm{I}_{55}$ & $\mathrm{I}_{55}$ \\
\hline $\mathrm{P}_{28}$ & $\mathrm{I}_{60}$ & $\mathrm{I}_{60}$ & $\mathrm{I}_{60}$ & $\mathrm{I}_{60}$ & $\mathrm{I}_{58}$ & $\mathrm{I}_{57}$ \\
\hline $\mathrm{P}_{29}$ & $\mathrm{I}_{61}$ & $\mathrm{I}_{61}$ & $\mathrm{I}_{61}$ & $\mathrm{I}_{61}$ & $\mathrm{I}_{59}$ & $\mathrm{I}_{59}$ \\
\hline $\mathrm{P}_{30}$ & $\mathrm{I}_{62}$ & $\mathrm{I}_{62}$ & $\mathrm{I}_{62}$ & $\mathrm{I}_{62}$ & $\mathrm{I}_{62}$ & $\mathrm{I}_{61}$ \\
\hline $\mathrm{P}_{31}$ & $\mathrm{I}_{63}$ & $\mathrm{I}_{63}$ & $\mathrm{I}_{63}$ & $\mathrm{I}_{63}$ & $\mathrm{I}_{63}$ & $\mathrm{I}_{63}$ \\
\hline
\end{tabular}

In the conventional Flash ADC, all the comparators are identical and reference voltages are generated by resistor ladder circuit. On the other hand, In the VSV comparator based Flash ADC, the desired internal reference voltage is generated by comparator itself just like TIQ comparator based Flash ADC. Therefore $2^{\mathrm{N}}-1$ different sizes of comparators are needed for generation of $2^{\mathrm{N}}-1$ reference voltages and resistor ladder network is not required for the external reference voltage generation.

\section{RESULTS \& DISCUSSION}

The proposed comparator has been simulated at $65 \mathrm{~nm}$ standard CMOS process with the supply voltage of $1.2 \mathrm{~V}$. The power is measured \& compared for both TIQ comparator [6] and proposed VSV comparator. It has been observed that the peak power for proposed VSV comparator is $96.37 \mu \mathrm{W} \&$ its average power is only $2.144 \mu \mathrm{W}$. While reported TIQ comparator [6] consumes peak power of $380 \mu \mathrm{W}$ and its average power is $26.407 \mu \mathrm{W}$. There is almost $70 \%$ reduction in the peak power. This is highly desirable for low power application of data conversion circuits. 
International Journal of VLSI design \& Communication Systems (VLSICS) Vol.5, No.3, June 2014

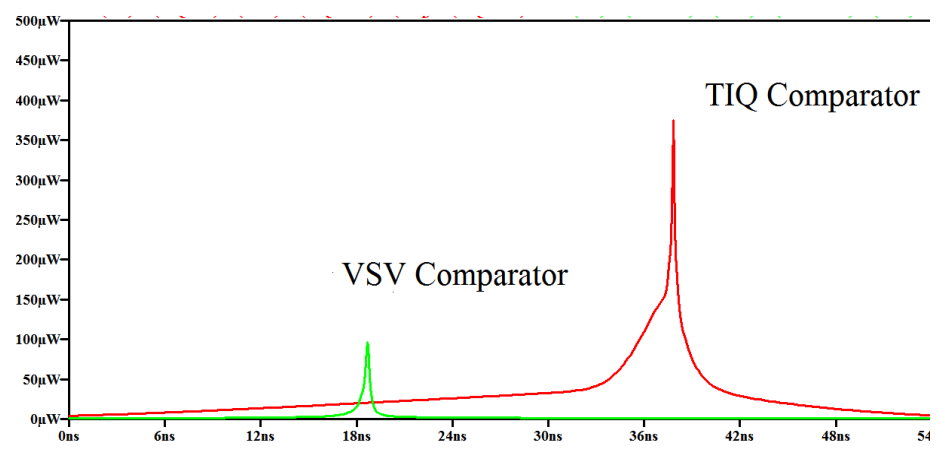

Figure 7. Power comparison of VTV comparator \& TIQ comparator

The comparison of power consumption between TIQ comparator and proposed VSV comparator is shown in figure 7. For 6-bit Flash ADC, the power consumption of TIQ comparator array and proposed VSV comparator array are shown in figure 9 and 10 respectively.

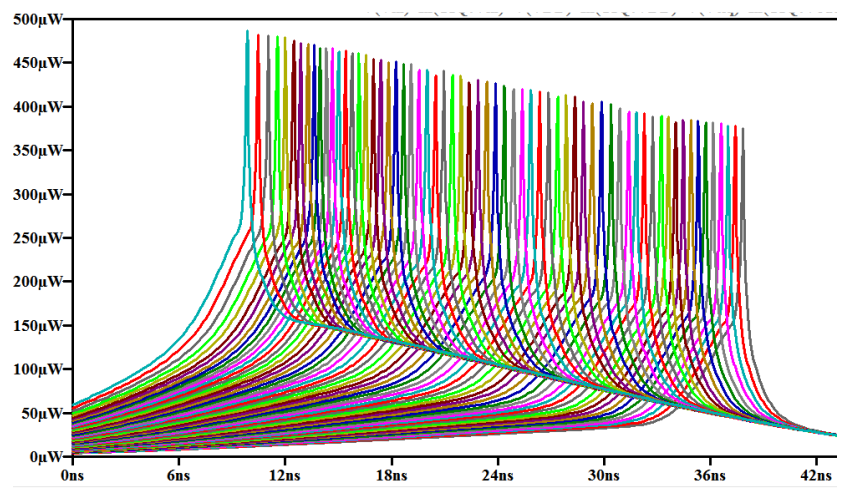

Figure 8. Power consumption of TIQ comparators array

Using the proposed comparator, a 6-Bit Flash ADC has been designed and simulated at 65nm standard CMOS process. The design is simpler than the conventional Flash ADC and it does not require the resistive ladder for reference voltage generation.

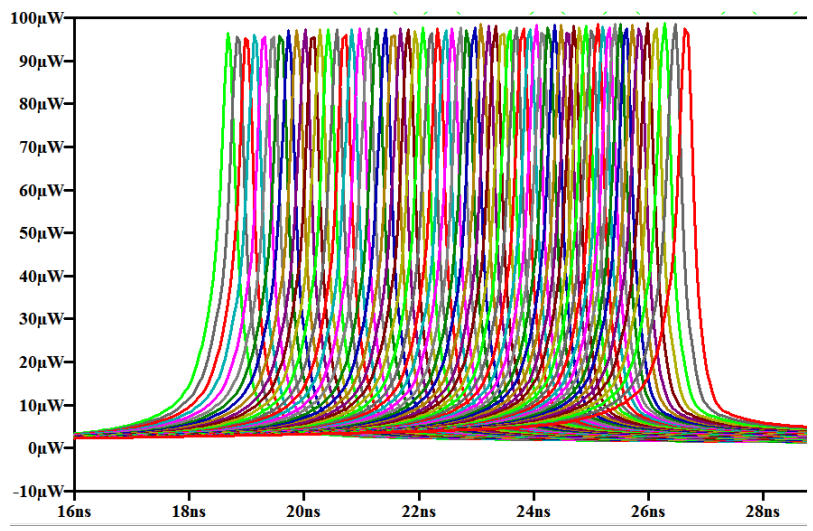

Figure 9. Power consumption of proposed VSV comparators array 
International Journal of VLSI design \& Communication Systems (VLSICS) Vol.5, No.3, June 2014

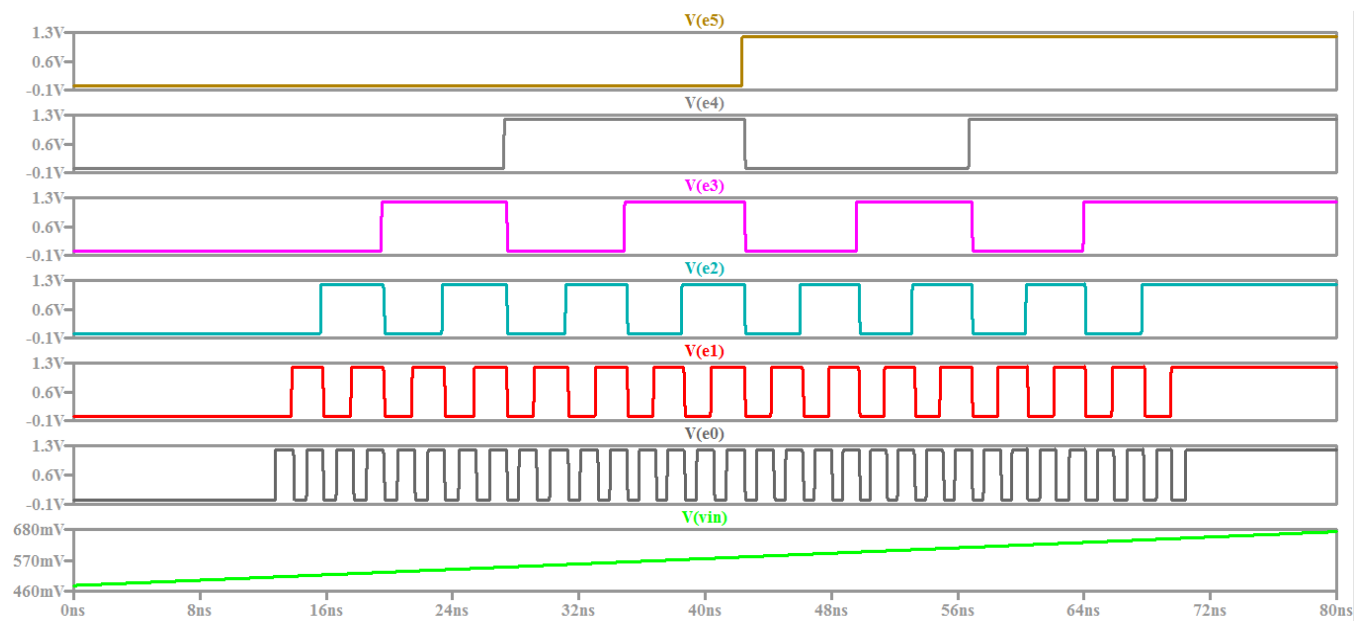

Figure 10. Transient analysis of the 6-bit Flash ADC

The transient analysis of the ADC is made by giving a ramp input signal ranging from $562 \mathrm{mV}$ to $680 \mathrm{mV}$ and each LSB voltage level is of $2.1 \mathrm{mV}$. The digital codes are obtained correctly for 6bit ADC as shown in figure 10. The plot of the measured differential nonlinearity (DNL) for the designed ADC is shown in figure 11.

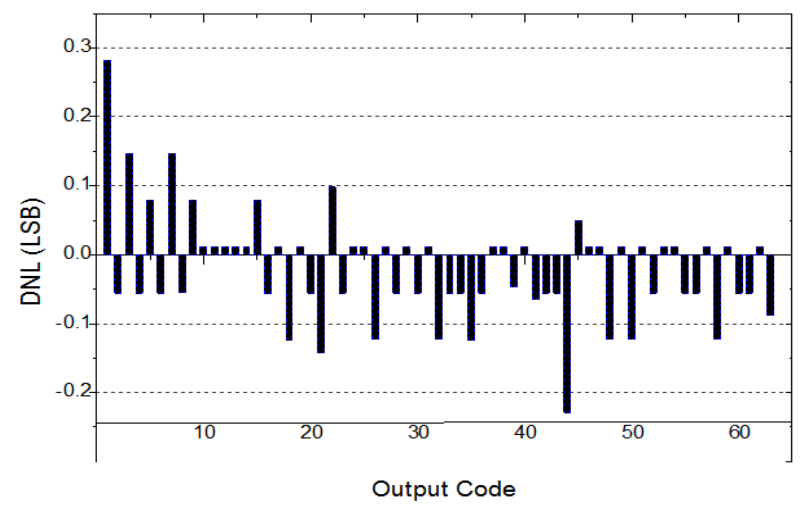

Figure 11.Measurement of DNL of the 6-Bit Flash ADC

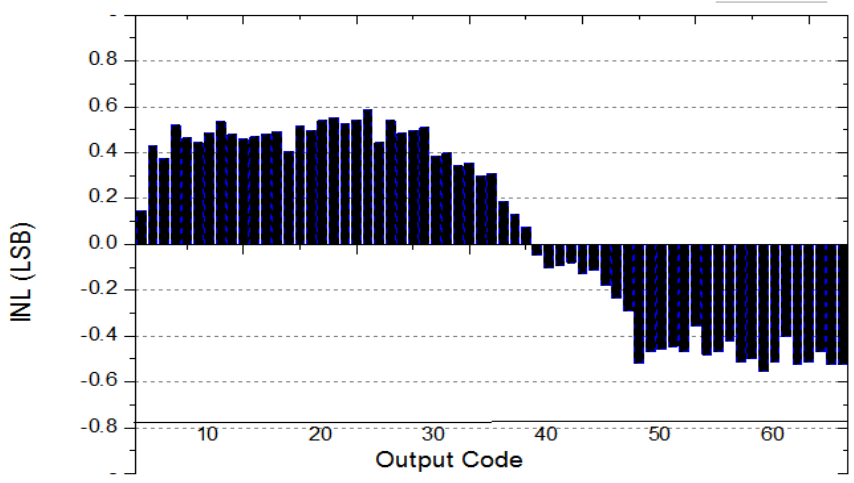

Figure 12. Measurement of INL of the 6-Bit Flash ADC 
International Journal of VLSI design \& Communication Systems (VLSICS) Vol.5, No.3, June 2014

The measurement of integral nonlinearity (INL) is drawn in the figure 12. It is clear from the plot that, the measured INL is lesser than 0.6 LSB. This shows functional correctness of the designed 6-bit Flash ADC

Table 2. Comparison Summary of Simulation Results

\begin{tabular}{|c|c|c|c|c|c|}
\hline Parameter & $\begin{array}{c}\text { Proposed } \\
\text { work }\end{array}$ & $\begin{array}{c}\text { Reported } \\
\text { work [1] }\end{array}$ & $\begin{array}{c}\text { Reported } \\
\text { work [2] }\end{array}$ & $\begin{array}{c}\text { Reported } \\
\text { work [3] }\end{array}$ & $\begin{array}{c}\text { Reported } \\
\text { work [10] }\end{array}$ \\
\hline Resolution & 6 -bit & 6-bit & 6 -bit & 6 -bit & 6-bit \\
\hline Architecture & Flash & Flash & Flash & Flash & Flash \\
\hline Technology & $65 \mathrm{~nm}$ & $90 \mathrm{~nm}$ & $130 \mathrm{~nm}$ & $65 \mathrm{~nm}$ & $250 \mathrm{~nm}$ \\
\hline DNL (LSB) & 0.3 & 0.5 & 0.4 & 0.5 & -- \\
\hline INL (LSB) & 0.6 & 0.96 & 0.6 & 0.5 & -- \\
\hline Voltage Supply & $1.2 \mathrm{~V}$ & $0.9 \mathrm{~V}$ & $1.2 \mathrm{~V}$ & $1.2 \mathrm{~V}$ & $2.5 \mathrm{~V}$ \\
\hline Power Dissipation & $2.1 \mathrm{~mW}$ & $98 \mathrm{~mW}$ & $90 \mathrm{~mW}$ & $12 \mathrm{~mW}$ & $66.8 \mathrm{~mW}$ \\
\hline Samples/sec. & $1 \mathrm{G}$ & $3.5 \mathrm{G}$ & $600 \mathrm{M}$ & $800 \mathrm{M}$ & $1 \mathrm{G}$ \\
\hline Ladder Network & No & Yes & Yes & Yes & No \\
\hline
\end{tabular}

The different parameters obtained for 6-bit Flash ADC are compared with earlier reported work in Table 2. For transparent comparison, only Flash ADC architectures of 6-bit resolution have been selected. It can be observed from the above table that the proposed comparator based Flash ADC consume the lowest power at the speed of $1 \mathrm{GHz}$. The measured DNL and INL are also lesser than 1 LSB. This guarantees that, the designed 6-bit flash ADC is monotonic in nature.

\section{CONCLUSION}

A 6-bit Flash ADC has been designed by employing the proposed VSV comparator. The design has been carried out in digital $65 \mathrm{~nm}$ standard CMOS technology. Further lower feature size and smaller supply voltage can be incorporated in the design. At $1 \mathrm{GHz}$ speed, the Flash ADC dissipates peak power of $2.1 \mathrm{~mW}$ and average power of only $244 \mu \mathrm{W}$. The measured maximum differential and integral nonlinearities (DNL and INL) for a ramp input are found to be 0.3 LSB \& 0.6 LSB respectively. The parameters DNL \& INL are improved as compared to earlier reported works. The designed 6-bit Flash ADC exhibits significant improvement in terms of power and speed of previously reported Flash ADCs. This makes it highly suitable ADC for high speed and low power application.

\section{REFERENCES}

[1] Deguchi, K., Suwa, N., Ito, M., Kumamoto, T., \& Miki, T. (2008) “A 6-bit 3.5-GS/s 0.9-V 98-mW flash ADC in 90-nm CMOS. IEEE Journal of Solid-State Circuits”, Vol. 43, No. 10, pp2303-2310.

[2] Kuttner, A. S. T. H. F., Sandner, C., \& Clara, M. (2005) “A 6bit, 1.2 gsps low-power flash-adc in 0.13 $\mu \mathrm{m}$ digital cmos", IEEE Journal of Solid-State Circuits Vol. 40, No.7.

[3] Chen, C. Y., Le, M. Q., \& Kim, K. Y. (2009) "A low power 6-bit flash ADC with reference voltage and common-mode calibration", IEEE Journal of Solid-State Circuits, Vol. 44, No. 4, pp1041-1046.

[4] Daly, D. C., \& Chandrakasan, A. P. (2009) "A 6-bit, 0.2 V to 0.9 V highly digital flash ADC with comparator redundancy. IEEE Journal of Solid-State Circuits” Vol. 44, No.11, pp3030-3038. 
International Journal of VLSI design \& Communication Systems (VLSICS) Vol.5, No.3, June 2014

[5] Segura, J., Rossello, J. L., Morra, J., \& Sigg, H. (1998) "A variable threshold voltage inverter for CMOS programmable logic circuits", IEEE Journal of Solid-State Circuits, Vol. 33, No.8, pp12621265.

[6] Tangel, A., \& Choi, K. (2004) "The CMOS Inverter as a comparator in ADC designs", Analog Integrated Circuits and Signal Processing, Vol. 39, No.2, pp147-155.

[7] Rabaey, J. M., Chandrakasan, A. and Nikolic', B. (2003) "Digital Integrated Circuits", 2nd Edition.

[8] Baker, R. J. (2005) "CMOS: Circuit Design, Layout and Simulation", IEEE Press Wiley India Edition.

[9] Torfs, G., Li, Z., Bauwelinck, J., Yin, X., Van der Plas, G., \& Vandewege, J. (2011) “Low-power 4bit flash analogue to digital converter for ranging applications", Electronics letters, Vol. 47, No.1, pp 20-22.

[10] Yoo, J., Choi, K., \& Tangel, A. (2001). "A 1-GSPS CMOS flash A/D converter for system-on-chip applications", In Proceedings of IEEE Computer Society Workshop on VLSI, pp. 135-139.

[11] Nuzzo, P., Van der Plas, G., De Bernardinis, F., Van der Perre, L., Gyselinckx, B., \& Terreni, P. (2006) "A $10.6 \mathrm{~mW} / 0.8 \mathrm{pJ}$ power-scalable $1 \mathrm{GS} / \mathrm{s}$ 4b ADC in $0.18 \mu \mathrm{m}$ CMOS with $5.8 \mathrm{GHz}$ ERBW", In Proceedings of the 43rd annual Design Automation Conference ,pp. 873-878.

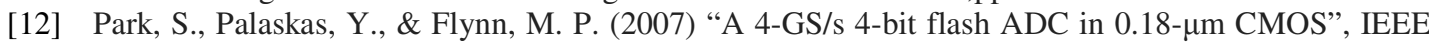
Journal of solid-State Circuits, IEEE Journal of Vol. 42, No.9, pp1865-1872.

[13] Sundström, T., \& Alvandpour, A. (2010) "A 6-bit 2.5-GS/s flash ADC using comparator redundancy for low power in $90 \mathrm{~nm}$ CMOS”, Analog Integrated Circuits and Signal Processing, Vol. 64, No.3, pp215-222.

[14] Van der Plas, G., Decoutere, S. \& Donnay, S. (2006) “A 0.16 pJ/conversion-step 2.5 mW 1.25 GS/s $4 \mathrm{~b}$ ADC in a 90nm digital CMOS process", IEEE International Solid-State Circuits, Digest of Technical Papers, p. 2310.

[15] Choi, M., \& Abidi, A. A. (2001) “A 6-b 1.3-Gsample/s A/D converter in 0.35- $\mu \mathrm{m}$ CMOS”, IEEE Journal of Solid-State Circuits, vol. 36, no. 12, pp. 1847-1858.

\section{AUTHORS}

Gulrej Ahmed has received his B.E. (Electronics and Instrumentation Engineering) in 2001 from the SGSITS, Indore, India. He has received M. E. (Digital Communication) in 2006 from I.E.T. DAVV, Indore. He is currently pursuing PhD from MANIT, Bhopal, India. His research interest includes Low Power Design of VLSI circuits, Data Converters and Mixed Signal Design.

Rajendra Kumar Baghel has received his B.E. in Electronics \& Communication Engineering from Government Engineering College, Jabalpur, India. He earned his M.Tech \& PhD from MANIT, Bhopal, India. He has teaching experience of more than 20 years and he is currently working as Professor of Electronics and Communication Engineering at MANIT, Bhopal. His main areas of interest \& research are Circuit \& Systems, Low power VLSI design and Data Converters.
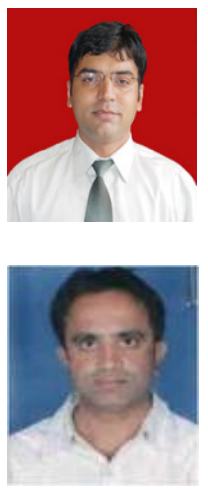